\title{
Vertical Axis Wind Turbine Improvement using DC-DC Boost Converter
}

\author{
Khairunnisa Khairunnisa ${ }^{1, *}$, Syaiful Rachman ${ }^{1}$, Edi Yohanes $^{1}$, Awan Uji Krismanto ${ }^{2}$, \\ Jazuli Fadil $^{3}$, Soedibyo Soedibyo ${ }^{3}$, Mochamad Ashari ${ }^{3}$, and Mahmoud Abuzalata ${ }^{4}$ \\ ${ }^{1}$ Department of Electrical Engineering, Politeknik Negeri Banjarmasin, Jl. Brig Jend. H. Hasan Basri, \\ Banjarmasin 70124, South Kalimantan, Indonesia \\ ${ }^{2}$ Department of Electrical Engineering, Institut Teknologi Nasional, Jl. Sigura - Gura No.2 \\ Sumbersari, Malang 65152, East Java, Indonesia \\ ${ }^{3}$ Department of Electrical Engineering, Institut Teknologi Sepuluh Nopember, Jl. Raya ITS, Keputih \\ Sukolilo, Surabaya, East Java, 60111 Indonesia \\ ${ }^{4}$ Department of Electrical Engineering, Polytechnic Palestine University, Wad Al-Hareya, Hebron, \\ West Bank, Palestine
}

\begin{abstract}
Vertical axis wind turbine (VAWT) can be operated in any direction of wind speed, but it has low rotation. To improve the performance of VAWT in which low rotation, this paper presents a simple control strategy of VAWT using a DC-DC boost converter to tap constant voltage in a standalone application. The main objective of this research is to maintain a constant output voltage of converter despite variation input voltage affected by variable wind speed. A simple proportional-integral (PI) controller has been used for a DC-DC boost converter and tested in MATLAB-Simulink environment, with the closed-loop system of the converter maintain constant output voltage although the wind speed is kept changing. The PI controller obtains the feedback from the output voltage of the boost converter to produce the correct pulse width modulation (PWM) duty cycle and trigger the metal oxide semiconductor field effect transistor (MOSFET) following the reference voltage of the turbine. This system has suppressed the value of overshoot and increased the efficiency of wind turbines as $34 \%$.
\end{abstract}

Keywords: Control modelling, energy conversion, pulse width modulation, transient, voltage control.

\section{Introduction}

Wind energy conversion is the transformation of energy from wind kinetic energy into mechanical energy using turbine rotor blades. Turbine rotor shafts are connected to generators that produce electrical energy. The main source of energy for the wind turbine is the wind speed which is key to producing the maximum power output. There are many advantages of wind turbines compared to conventional plants such as diesel generators and

*Corresponding author : khairunnisa@ poliban.ac.id 
other fossil fuel plants. The advantages of wind turbines are that they are environmentally friendly, inexpensive and the capability to reduce $\mathrm{CO}_{2}$ emissions [1].

Wind speed is an important parameter in a wind energy conversion system, especially in converting mechanical power output into electrical energy. For producing optimal power, the control method needs to be carefully designed. Besides, a control method is needed so that the turbine can still operate safely in a wide range of wind speeds. So that the turbines work remains protected even when wind speed is excessive [2].

There are two types of wind turbines based on turbine rotation orientation, namely the horizontal axis wind turbine (HAWT) and vertical axis wind turbine (VAWT) [2]. Currently, both of these turbine technologies continue to be developed to achieve better efficiency in terms of blade design and electronic control to overcome dynamic wind speeds. Based on the Betz limit theory, HAWT has better efficiency than VAWT. But VAWT also has many advantages including being able to operate in all wind directions and generators can be placed closer to the ground. VAWT is very suitable for stand-alone applications in the remote area [1].

There are two types of wind turbine control systems, namely fixed speed wind turbines and variable speed wind turbines. Fixed speed wind turbines rotate at constant wind speed so fluctuating winds will cause efficiency to decrease. Variable speed wind turbines can extract maximum power over a wide range of wind speeds [2]. To control the wind turbine, the generator is connected to the power converter. One generator that is widely used for VAWT is a permanent magnet generator (PMSG) for the conversion of mechanical power into electrical power. Next, PMSG is connected to a power converter. There are several topology converters used in wind turbines, including the DC-DC boost converter, buck converter, buck-boost converter and many other variants of converters that have been developed by researchers. DC-DC converters are widely used to maintain output voltage when input voltage changes [3, 4].

Several control techniques have been proposed to improve stability with fast transient responses such as fuzzy control, PID control, Particle Swarm Optimization, Genetic Algorithm and many others that have been developed by researchers. In advanced controllers, they use maximum power point tracking to extract maximum power in wider wind speeds, like perturb and observe $(\mathrm{PnO})$. This algorithm has a fast response to find the peak power point of the wind turbine $[1,5,6]$.

This paper presents a dynamic model of stand-alone type vertical axis wind turbines with a small scale. VAWT rotors designed to determine the type and capacity of the generator so that the right power converter parameters can be determined based on optimum mechanical and electrical power. The power converter using a PI controller to set the duty cycle on the boost converter to enhance the constant voltage output. The PI controller is tuned using trial and error to find the appropriate values of PI gains. The results are compared with the conventional boost converter which is operated without the PI controller to see the differences in transient voltage output.

\section{VAWT modelling}

The vertical axis wind turbine or VAWT rotates based on the rotary axis which is perpendicular to the ground. Based on Figure 1, the generator is connected to a hub or rotor blade to convert mechanical power into electrical power. The power generated depends on the wind speed that rotates the turbine to produce kinetic energy with the following Equation (1):

$$
\mathrm{KE}=\frac{1}{2} m v^{2}
$$




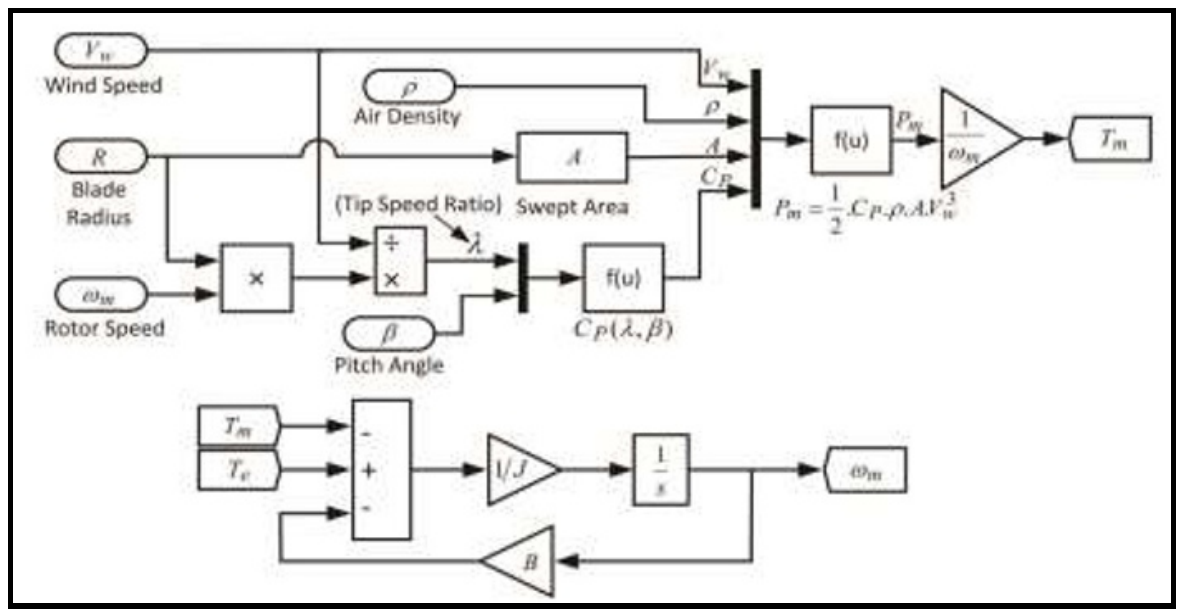

Fig. 1. Dynamic model of wind turbine [7].

The following is the Equation (2) where the power P indicates the amount of density of wind energy generated from the movement of the wind that will pass through the swept area or the width of the sweep of blade A:

$$
\mathrm{P}=\frac{\text { Energy }}{\text { Time }}=\frac{1}{2}\left(\frac{\text { Energy }}{\text { Time }}\right) v^{2}
$$

Below (Equation (3) is the speed of the density of air that crosses a swept area $A$ is the product of the density of air $\rho$ and velocity $(v)$ :

$$
m=\rho \cdot A \cdot v
$$

Then the power of wind speed through a swept area can be represented as Equation (4):

$$
\mathrm{P}_{\text {available }}=\frac{1}{2} \cdot \rho \cdot A \cdot v^{3}
$$

$\mathrm{P}_{\text {available }}$ is the power available in the wind (W) with the period of air type $\rho\left(\mathrm{kg} \mathrm{m}^{-3}\right)$, $\mathrm{v}^{3}$ is the wind speed $\left(\mathrm{m} \mathrm{s}^{-1}\right)$. A is a swept area formed by sweeping the bladethat crosses the air. For VAWT with the type of straight blade, the swept area is the result of multiplying the diameter of the turbine and the height of the blade in the meter precision. That is Equation (5):

$$
A=h \cdot D
$$

$D$ is the diameter of the turbine and $h$ is the height of the turbine blade (m).

Figure 2 shows that the VAWT with straight blade type and the wind will pass through the swept area in any direction and transform wind energy into mechanical energy. Where the swept area is the result of multiplying the diameter of the turbine and the height of the blade. The transformation of kinetic energy into mechanical energy converted using VAWT can be expressed in Equation (6) and Equation (7) as follows:

$$
\begin{gathered}
\mathrm{P}_{\mathrm{m}}=\frac{1}{2} \cdot \rho \cdot A \cdot v^{3} \cdot C_{p}(\theta, \lambda) \\
\mathrm{T}_{\mathrm{m}}=\frac{\mathrm{P}_{\mathrm{m}}}{\omega_{\mathrm{m}}}=\frac{\frac{1}{2} \cdot \rho \cdot A \cdot v^{3} \cdot C_{p}(\theta, \lambda)}{\omega_{\mathrm{m}}}
\end{gathered}
$$




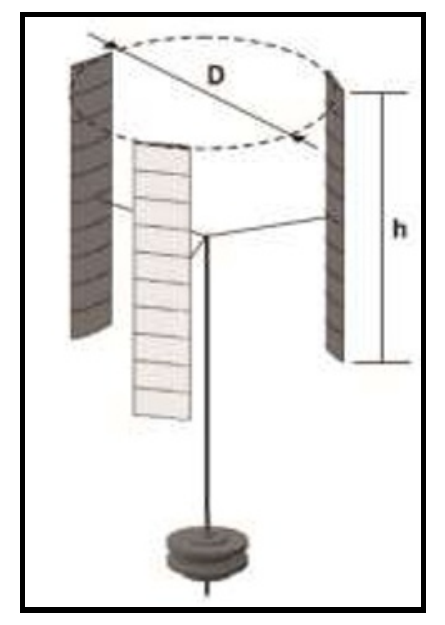

Fig. 2. Swept area of VAWT.

Where $C_{p}(\theta, \lambda)$ is the blade coefficient parameter and the function of the pitch angle $\theta$ is also the ratio of the tip speed of the blade $\lambda$, Equation 6 is used to calculate turbine power [7]. the tip speed ratio of the bladeis the ratio between the tip speed of the blade and the wind speed [8]. $T_{m}$ is the mechanical torque of the turbine in N.m and $\omega_{m}$ is the speed of the turbine mechanical angle in $\mathrm{rad} \mathrm{s}^{-1}$ [9]. Tip speed ratio can be expressed in Equation (8) as follows:

$$
\lambda=\frac{r \omega}{\mathrm{v}_{w}}
$$

Where $r$ is the radius of the turbine, $v_{w}$ is the wind speed and $\omega$ is the turbine rotational speed [10]. Mechanical angular velocity can be represented in Equation (9) as follows:

$$
J \frac{d \omega_{m}}{d_{t}}=T_{e}-T_{m}-B \cdot \omega_{m}
$$

Where $J$ is the combination of inertia of the wind turbine and rotor $\left(\mathrm{kg} \mathrm{m}^{-2}\right), T_{e}$ is electromagnetic torque $(\mathrm{N} \mathrm{m})$, and $B$ is rotor friction $\left(\mathrm{N} \mathrm{m} \mathrm{s} \mathrm{rad}^{-1}\right)$ [10].

Based on several equations above, it can be concluded that there are four main parameters that affect turbine mechanical power output, namely wind speed, swept area, air density and $C_{p}$ [11]. For swept efficiency the area depends on the fabrication or design while the density of air is a constant value. Mechanical power output is also affected by turbine rotor speed. The maximum turbine mechanical power output at maximum wind speed is only at the optimum rotor speed [12], which is the maximum $C_{p}$ value with an optimum tip speed ratio. The parameters used for vertical axis wind turbines are as follows:

Table 1. Parameter geometry of VAWT.

\begin{tabular}{|l|l|c|}
\hline No & \multicolumn{1}{|c|}{ Wind Turbine } & $\begin{array}{c}\text { Vertical } \\
\text { Axis }\end{array}$ \\
\hline 1 & Blade Height $(\mathrm{m})$ & 1 \\
\hline 2 & Swept Area $\left(\mathrm{m}^{2}\right)$ & 1 \\
\hline 3 & Number of Blade & 3 \\
\hline 4 & Radius $(\mathrm{m})$ & 0.5 \\
\hline 5 & Chord Length $(\mathrm{mm})$ & 200 \\
\hline 6 & Airfoil & NACA 4412 \\
\hline
\end{tabular}




\section{PWM of DC-DC converter}

This DC-DC converter control circuit is better known as pulse width modulation (PWM). Where this circuit forms a large pulse of the duty cycle system used. It isproduced by generating pulses with a certain period according to the desired design in controlling the converter circuit switching process. The duty cycle (D) is defined as the ratio between the switch time on the $T_{s}$ period. This comparison is usually expressed as a percentage. Mathematically the definition can bewritten as follows in Equation (10):

$$
D=\frac{T_{o n}}{T_{s}} 100 \%
$$

$\mathrm{D}=$ Duty Cycle

$\mathrm{T}_{\text {on }} \quad=$ Priode of time on

$\mathrm{T}_{\mathrm{s}} \quad=$ Priode of time PWM signal

DC-DC boost converter is a power supply component that is not isolated, where the output voltage is greater than the input. The DC-DC converter consists of at least a FET power switch (MOSFET Q) and a diode with inductor (L) as energy storage. Use of capacitor filters in order to eliminate ripples from the output voltage. The DC-DC boost amplifier is operated continuously or the intermittent mode depends on the inductor current. PWM control power has a "on" and "off" state. This situation is shown in Figure 3 and Figure 4 respectively. Total duration of status $\mathrm{ON}$ at $\mathrm{T}$ and the $\mathrm{Q}$ switch is active, and the $\mathrm{T}$ OFF status when switching $\mathrm{Q}$ is inactive in continuous conduction mode given by Equation (11) and Equation (12). Where, duty cycle (d) is a cycle governed by a control circuit, where $\mathrm{d} \mathrm{T}$ is a transition period for one cycle.

$$
\begin{aligned}
& t_{\text {on }}=t_{s} d \\
& t_{\text {off }}=t_{s}(d-1)
\end{aligned}
$$

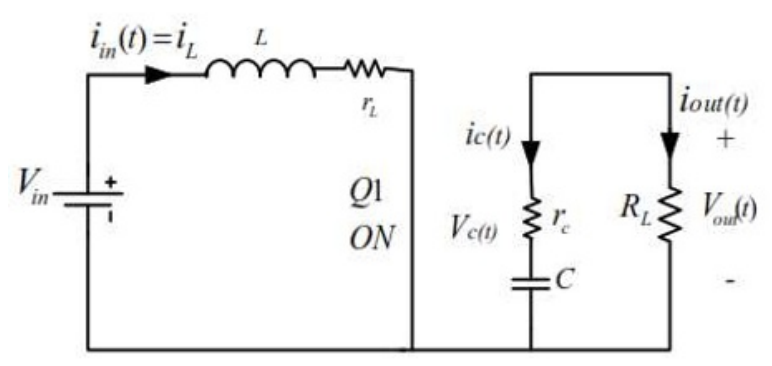

Fig. 3. Bosst converter $0<\mathrm{t}<\mathrm{T}_{\text {on }}$. 


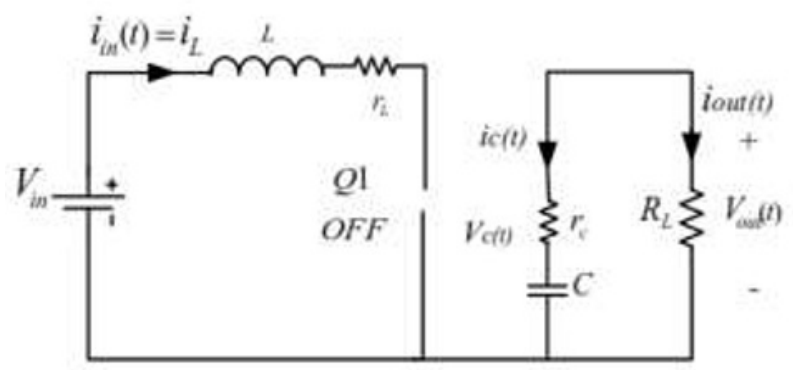

Fig. 4. Boost converter $T_{\text {on }}<t<\mathrm{T}$.

Steady state input for voltage output conversion ratio is given by Equation (13):

$$
V_{\text {out }}=\frac{V_{\text {in }}}{1-d}
$$

The size of the inductor'speak-to-peak current ripple $\Delta \mathrm{I}_{\mathrm{L}}$ is given by Equation (14):

$$
\Delta I_{L}=\frac{V_{\text {in }} d}{f_{s} L}
$$

And also the capacitor voltage output ripple $\Delta \mathrm{V}_{\mathrm{c}}$ is given by Equation (15):

$$
\Delta V_{c}=\Delta V_{\text {out }}=\frac{I_{o} d}{f_{s} C}
$$

The state spase of the average state is used to model the DC-DC converter by considering the parameters of the system component. transfer function of the system is used to analyze the dynamic conditions of the system. In general, the average representation of a converter is expressed as in Equation (16) and Equation (17)

$$
\begin{aligned}
\dot{X}(t) & =\bar{A} x(t)+\bar{B} u(t) \\
y(t) & =\bar{C} x(t)
\end{aligned}
$$

Based on the boost converter (Figure 3) when the $Q$ switch is active, and when the stady state is activated, and Kirchof Law applies the KVL and KCL converters, the cycle matrix with $d$ as the weighting factor is obtained as the following matrix Equation (18), Equation (19) and Equation (20):

$$
\begin{aligned}
& \bar{A}=\left[\begin{array}{ll}
\left(R_{o n}+r_{L}\right) d+\left(r_{L}+R_{L} / / r_{C}\right)(1-d) & \frac{R_{L}(1-d)}{L\left(R_{L}+r_{C}\right)} \\
\frac{R_{L}(1-d)}{C\left(R_{L}+r_{C}\right)} & \frac{1}{C\left(R_{L}+r_{C}\right)}
\end{array}\right] \\
& \bar{B}=\left[\begin{array}{c}
\frac{1}{L} \\
0
\end{array}\right] \\
& \bar{C}=\left[R_{L} / / r_{C}(1-d)\right] \frac{R_{L}}{R_{L}+r_{C}}
\end{aligned}
$$

To analyze dynamic conditions and design of controllers for DC-DC converters, MATLAB state space is used in the form of space-state using the command transfer function to control the converter and get the Gvd converter output (s), while the converter is designed based on parameters steady state which is presented as needed. 
Figure 5 shows that the DC-DC boost converter is connected to PMSG and three phases diode rectifier. The circuit consist of inductor, capacitor, diode, and mosfet as the switching component to generating pulses with PID controller. In the discussion of the controller designed for the converter DC-DC converter, analysis of the input controller forms a unit with the feedback that was first analyzed. The transient response presented in Figure 8 shows that the system has an overshoot with several oscillations, up time and completion time with a time response. To eliminate the overshoot system and improve the temporary response and also eliminate steady-state errors [13], it is necessary to design a PID controller using three different tuning methods.

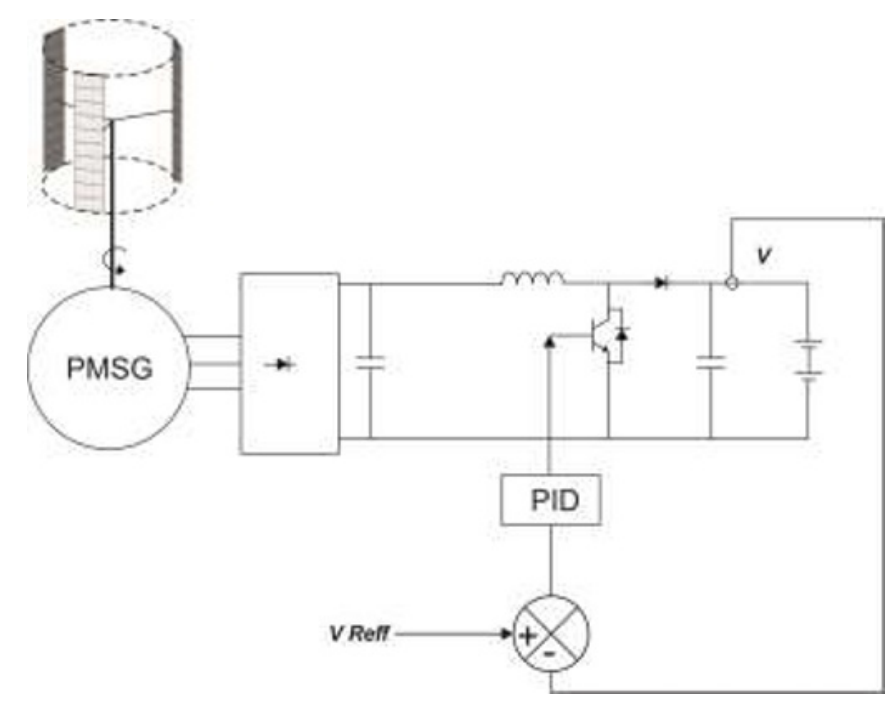

Fig. 5. VAWT With DC-DC Boostconverter

The integral and proportional derivative controller (PID) is considered to be the most studied and used controller because of its simplicity and robustness (Equation (21)).

$$
u(t)=k_{s} e(t)+K_{i} \int_{0}^{t} e(t)+K_{d} \frac{d e(t)}{d t}
$$

The above relationship equation in the domain-stransfer function of the PID controller is given by Equation (22) as follows :

$$
C(s)=k_{p}+\frac{K_{i}}{S}+K_{d} S
$$

Where, $\left(\mathrm{K}_{\mathrm{i}}\right)$ and $\left(\mathrm{K}_{\mathrm{d}}\right)$ are the integration gain and derivative gain of each constant.

\section{Results and discussion}

There are several parameters for determining a closed loop system, namely, rise time, overshoot, settling time, and the steady state error. Rise time is the time needed by the converter's output starting from the first time the system is run until it reaches the desired level. Overshoot is the value of the peak level measured from the steady state. Settling time is the time needed by the system to converge the steady state. Steady state error is the difference between the steady state output and the desired output. Each PID control action has certain advantages. Proportional control action has the advantage of rapid rise time, 
integral control action has the advantage of minimizing errors, and derivative control actions have the advantage of minimizing errors or reducing overshoot/undershoot. Thus, in order to produce an output with a fast rise time and a small error, these three control actions can be combined into a PID control action. Figure 6 shows that the feedback obtain from output voltage of converter and compared with reference voltage to minimize error with PID controller.

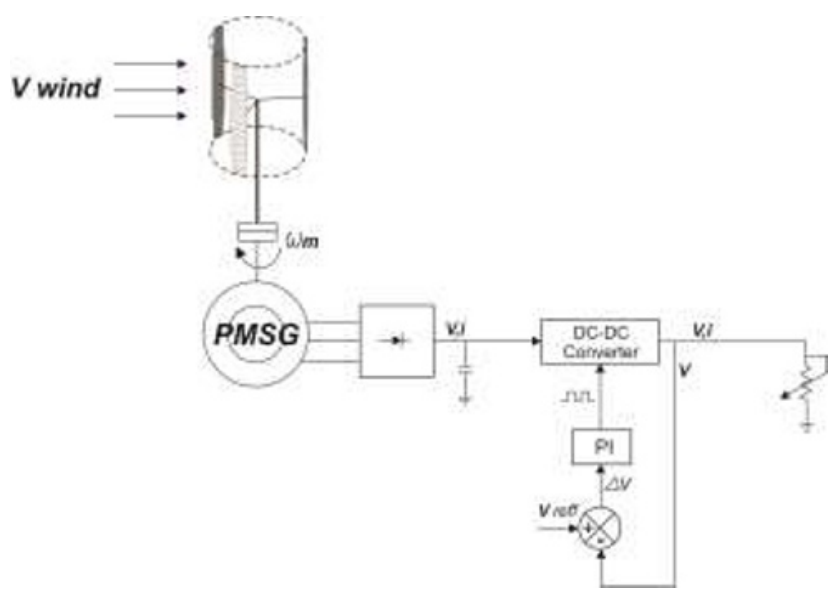

Fig. 6. PID controller concept for VAWT.

Table 2. Parameter of boost converter.

\begin{tabular}{|c|l|c|}
\hline No & \multicolumn{1}{|c|}{ Parameter } & Value \\
\hline 1 & Input Voltage & $12 \mathrm{~V}$ \\
\hline 2 & Output Voltage & $24 \mathrm{~V}$ \\
\hline 3 & BoostInductor & $92 \mu \mathrm{H}$ \\
\hline 4 & FilterCapacitor & $378 \mu \mathrm{F}$ \\
\hline 5 & ResistiveLoad & $25 \Omega$ \\
\hline 6 & Duty Cycle & 0.5 \\
\hline 7 & $\mathrm{~K}_{\mathrm{p}}$ & 0.001 \\
\hline 8 & $\mathrm{~K}_{\mathrm{i}}$ & 0.01 \\
\hline
\end{tabular}

The modeling results from VAWT are shown in the Figure 7 . Where the optimum power that can be achieved is $480 \mathrm{~W}$ at a constant wind speed of $12 \mathrm{~m} \mathrm{~s}^{-1}$ with a turbine rotational speed at $280 \mathrm{rpm}(1 \mathrm{rpm}=1 / 60 \mathrm{~Hz})$. 


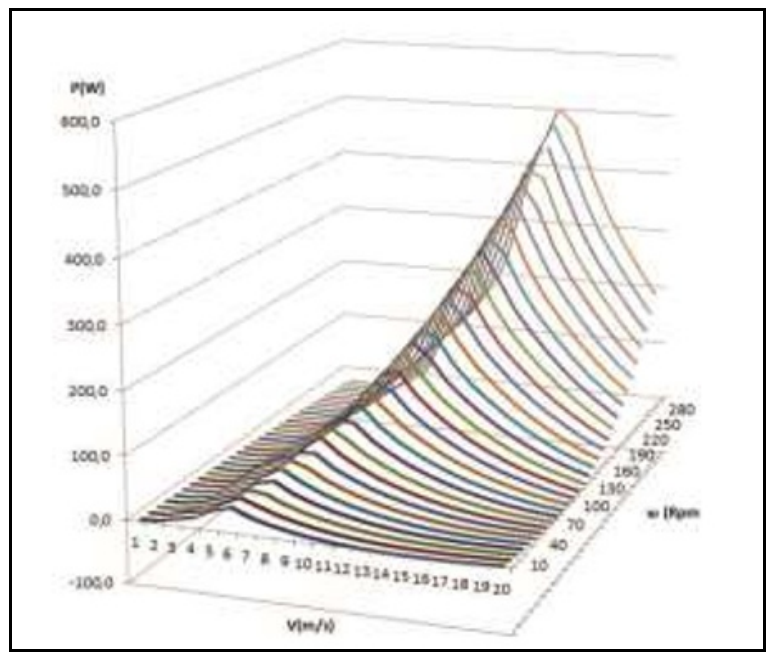

Fig. 7. The power curve of VAWT.

At a constant wind speed of $12 \mathrm{~m} \mathrm{~s}^{-1}$ by ignoring the mechanical losses the PMSG output voltage is $12 \mathrm{Vac}$ and becomes an input rectifier with an output voltage of $12 \mathrm{Vdc}$ and becomes used as a boost converter input. The simulation done under closed loop conditions with a PI controller that reduced steady state error close to zero and improves the dynamic response of the converter as shown in Figure 9, the output voltage is close to the target voltage and reduce over shoot from $54.16 \%$ to $12.5 \%$ with settling time $0.086 \mathrm{~s}$. The loadis a constant resistance of $25 \Omega$.

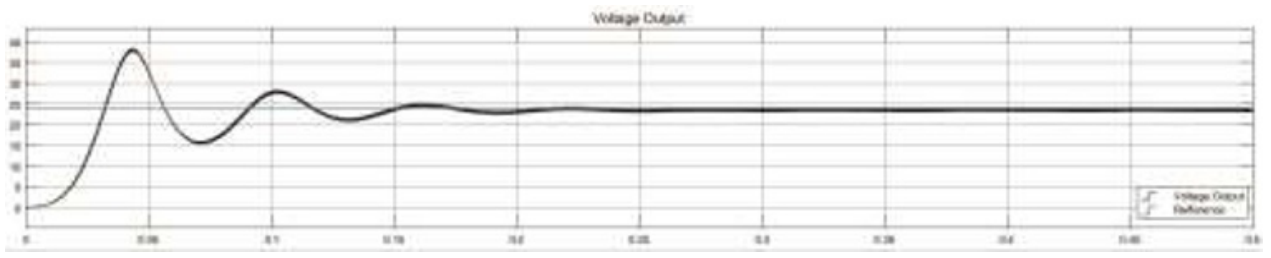

Fig. 8. Simulation result of conventional boost converter.
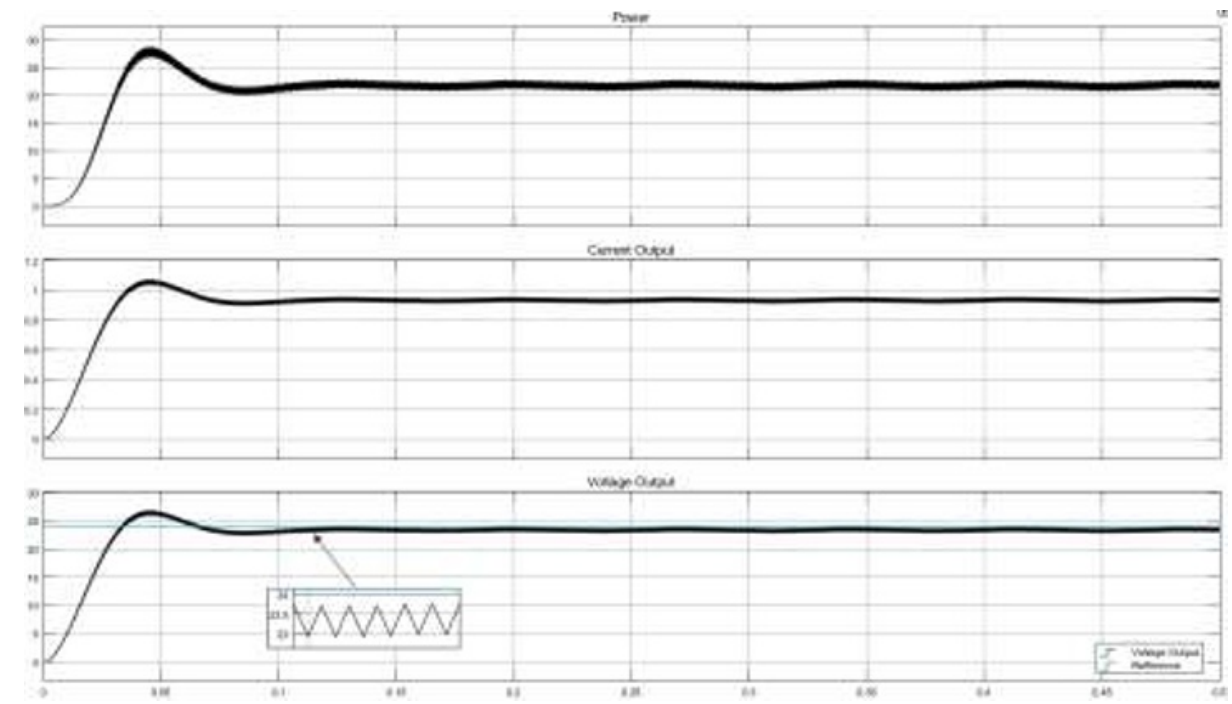

Fig. 9. Simulation result of boost converter with pi controller. 
Figure 9 shown that the refference voltage is $24 \mathrm{~V}$ with peak overshoot of output voltage is $12.5 \%$ with peak time is $0.04 \mathrm{~s}$ and rise time is $0.034 \mathrm{~s}$. The ripple output voltage is $0.78 \mathrm{~V}$ with switching frequency is $1.6 \mathrm{kHz}$. The system results show that the boost converter with a PI controller provides better output voltage regulation and over shoot reduction with settling time is $0.086 \mathrm{~s}$.

\section{Conclusion}

Based on simulation result, the proposed methode is better than the conventional boost converter. In which DC-DC Boost converter with the PI controller provides better voltage regulation and has a higher efficiency of $34 \%$, it can be observed that the voltage output remains constant in $24 \mathrm{~V}$ and over shoot reduction as well. The ripple voltage is $0.78 \mathrm{~V}$ with settling time is $0.086 \mathrm{~s}$

The author wouldlike to thank the Politeknik Negeri Banjarmasin, Institut Teknologi Sepuluh November and the Ministry of Research, Technology and Higher Education Republic of Indonesia for funding support (contract number: 014/SP2H/PPM/DRPM/2019) and to all those who have helped this research.

\section{References}

1. A. Merabet, J. Kerr, V. Rajasekaran, D. Wight. Power electronics circuit for speed control of experimental wind turbine. Paper Presented in 24th International Conference on Microelectronics (Algiers, Algeria, 2012).

https://ieeexplore.ieee.org/document/6471368

2. B. Wu, Y. Lang, N. Zargari, S. Kouro. Power conversion and control of wind energy systems. New York: IEEE Press (2011). p. 480.

https://ieeexplore.ieee.org/book/6047595

3. M.F. Adnan, M.A.M. Oninda. M.M. Nishat, N. Islam. IJERT 6,9:27-32(2017).

https://www.ijert.org/design-and-simulation-of-a-dc-dc-boost-converter-with-pidcontroller-for-enhanced-performance

4. V. Lazarov, D. Roy, D. Spirov, Z. Zarkov. New control strategy for variable speed wind turbine with $d c$-dc converters. Paper Presented in 14th International Power Electronics and Motion Control Conference, EPE-PEMC. (Ohrid, Republic of Macedonia, 2010).

https://ieeexplore.ieee.org/document/5606570

5. F.-Q. Chen, J.-M. Yang. Fuzzy PID controller used in yaw system of wind turbine. Paper Presented in International Conference on Power Electronics Systems and Applications (Hong Kong, China, 2009). https://ieeexplore.ieee.org/document/5228644

6. B. Hu, L. Chang, Y. Xue. Control and design of a novel buck-boost converter for wind turbine applications. Paper Presented in International Conference on Sustainable Energy Technologies (Singapore, Singapore, 2008).

https://ieeexplore.ieee.org/document/4747008

7. D. Kumar, K. Chatterjee. Renewable and Sustainable Energy Review 55:957970(2016). https://www.sciencedirect.com/science/article/abs/pii/S1364032115012654

8. J. Jhon. Mechanics of extendable wind turbine blades. [Thesis]. Department of Civil and Environmental Engineering, Colorado State University, USA (2015). p. 89.

https://mountainscholar.org/bitstream/handle/10217/166942/John_colostate_0053N_12 905.pdf; sequence $=1$ 
9. G.M.H. Shahariar, M.R. Hasan. Design and construction of a vertical axis wind turbine. Paper Presented in 9th International Forum on Strategic Technology (IFOST). (Chittagong, Bangladesh, 2014). IEEE, 326-329(2014).

https://ieeexplore.ieee.org/document/6991132

10. P.D.A. Aziz, A.K.R. Mohamad, F.Z. Hamidon, N. Mohamad, N. Salleh, N.M. Yunus. A simulation study on airfoils using VAWT design for low wind speed application. Paper Presented in 4th International Conference on Engineering Technology and Technopreneuship (ICE2T) (Kuala Lumpur, Malaysia, 2014). IEEE, 105-109(2014). https://ieeexplore.ieee.org/document/7006228

11. J. Fadil, Soedibyo, M. Ashari. Performance comparison of vertical axis and horizontal axis wind turbines to get optimum power output. The 15th International Conference on Quality in Reasearch (QIR): International Symposium on Electrical and Computer Engineering (Bali, Indonesia, 2017). IEEE, 429-433(2017).

https://ieeexplore.ieee.org/document/8168524

12. J. Fadil, Soedibyo, M. Ashari. Performance analysis of vertical axis wind turbine with variable swept area. Paper Presented in International Seminar on Intelligent Technology and Its Application 2017 (ISITIA) (Surabaya, Indonesia, 2017). IEEE, pp 231235(2017). https://ieeexplore.ieee.org/document/8124083

13. N. Tiwari, A.N. Tiwari. Performance analysis of unidirectional and bidirectional buckboost converter using PID controller. Paper Presented in 2nd International Conference on Electronics, Materials Engineering \& Nano-Technology (IEMENTech) (Kolkata, India, 2018). https://ieeexplore.ieee.org/document/8465229 